\title{
WADAH MUSIK INDIE LOKAL
}

\author{
Yohanes Rheza ${ }^{1)}$, Suwandi Supatra ${ }^{2)}$ \\ 1) Program Studi S1 Arsitektur, Fakultas Teknik, Universitas Tarumanagara, yohanes.rheza@gmail.com \\ 2) Program Studi S1 Arsitektur, Fakultas Teknik, Universitas Tarumanagara, ybhan@gmail.com
}

\begin{abstract}
Abstrak
Individualisme merupakan salah satu permasalahan yang terjadi dalam kehidupan masyarakat. Hal ini disebabkan oleh salah satunya kebiasaan manusia dalam menghabiskan sebagian besar waktunya bekerja dan beristirahat di rumah dan tanpa adanya kegiatan sosial yang dapat rutin dilakukan setiap hari dengan sesamanya, apalagi dengan adanya media sosial yang membuat manusia dapat berkomunikasi hanya dengan perangkat elektronik dan tidak bertemu secara langsung. Isu utama yang diangkat adalah "Open Architecture sebagai Third Place" yang membahas tentang bagaimana menciptakan sebuah tempat yang dapat menjadi Third Place sebagai tempat berkumpulnya komunitas masyarakat untuk bersosialisasi dan sebagai tempat publik informal. Isu lain yang di angkat adalah Musik Indie sebagai aliran musik yang sedang menjadi trend dalam industri musik saat ini. Lokasi proyek berada di Jalan Cikini Raya di Jakarta Pusat, yang dikenal sebagai salah satu kawasan seni dan wisata dengan adanya Taman Ismail Marzuki sebagai pusat kesenian dan kebudayaan. Tujuan dari proyek ini adalah menciptakan sebuah Third Place yang dapat menjadi tempat berkumpulnya masyarakat untuk berkomunitas dan untuk mendukung musisi indie dalam berkarya dan mengembangkan kemampuannya. Metode penelitian yang digunakan dalam penelitian ini adalah Survey Lapangan, Studi Literatur dan Studi Preseden. Hasil penelitian yang didapatkan adalah perancangan bangunan sebagai "Wadah Musik Indie Lokal". Program utama dalam proyek ini yaitu Indie Bar, Community Space, Music Studio, Music Store dan Music Classes yang bertujuan untuk mewadahi aktivtias sosial masyarakat bersamaan dengan musik indie yang dapat merangkul masyarakat menjadi satu komunitas bersama.
\end{abstract}

Kata Kunci: indie; komunitas; masyarakat; musik; sosial

\begin{abstract}
Individualism is one of the issues that occur in people's lives. One of the causes is one's habit in spending most of their time working and resting at home and without social activities that can be done every day with other individual, furthermore with the existence of social media that makes humans able to communicate with electronic devices and not meeting directly. The main issue is "Open Architecture as a Third Place" which discusses how to create a place that can become a Third Place as a gathering place for communities to socialize and as an informal public place. Another issue is Indie Music as a genre of music that is becoming a trend in the music industry today. The project site is located at Jalan Cikini Raya in Central Jakarta, known as one of the arts and tourism areas with Taman Ismail Marzuki as the center of arts and culture. The aim of this project is to create a Third Place where the society can become a community and to support indie musicians in making music and developing their abilities. The research methods used in this research are Site Survey, Literature Study and Precedent Study. The result obtained is the design of the building "Local Indie Music Quarter". The main programs in this project are the Indie Bar, Community Space, Music Studio, Music Store and Music Class that aim to facilitate social activities of the community together with indie music that can embrace the community into one community together.
\end{abstract}

Keywords: community; indie; music; social; society 


\section{PENDAHULUAN}

Dalam aktivitas sehari-hari manusia, ada 3 tempat utama yang selalu dikunjungi. Yang pertama atau First Place adalah rumah (home). Yang kedua atau Second Place ini pada umumnya berupa institusi tempat seseorang bekerja atau belajar yang memiliki jadwal tetap sehingga mengharuskan manusia untuk melakukan pekerjaan di tempat tersebut pada waktu dan hari tertentu secara terus menerus. Yang ketiga (third place) adalah tempat yang mewadahi kehidupan publik yang informal dan merupakan berbagai macam tempat publik yang menerima perkumpulan individu yang reguler, sukarela, informal, dan menyenangkan.

Third place adalah tempat yang seringkali tidak disadari masyarakat sebagai salah satu kebutuhan manusia, sehingga sampai sekarang, hanya sedikit atau bahkan tidak ada tempat yang memiliki karakter third place sebagaimana seharusnya. Masyarakat sudah sangat akrab dengan istilah mall atau café yang seringkali dijadikan sarana rekreasi kota dan tempat berkumpul antar individu untuk bersosialisasi. Namun masyarakat belum sepenuhnya sadar bahwa mall dan café pada umumnya merupakan bangunan komersil yang memiliki fungsi utama untuk menjual produk atau pelayanan dengan tujuan mendapatkan keuntungan, dan tidak secara khusus bertujuan untuk menyediakan ruang bagi masyarakat untuk menetap lama, bersosialisasi, dan berkomunitas. Masyarakat membutuhkan lebih dari sekedar mall atau café. Setiap manusia membutuhkan kehidupan sosial, dimana ia dapat berinteraksi sosial dengan sesamanya secara bebas tanpa ada batasan-batasan status sosial atau formalitas lainnya dan masyarakat membutuhkan ruang untuk mewadahi aktivitas tersebut yang terbuka untuk komunitas umum. Tempat ini adalah Third place (Oldenburg, 1989)

Dalam proyek ini, Third place dibangun untuk melayani kawasan Cikini, yang memiliki ciri khas sebagai salah satu pusat kesenian dan kebudayaan di Jakarta. Berdasarkan ciri khas yang dimiliki kawasan, Third place menyediakan program yang mengacu pada bidang kesenian dan kebudayaan, yaitu Wadah Musik Indie Lokal. Third place disini selain menyediakan tempat untuk berkumpulnya komunitas bagi masyarakat lokal, juga menyediakan sebuah tempat dimana musisi, penggemar musik, dan anggota industri musik untuk berkumpul bersama dan berkomunitas.

\section{KAJIAN TEORITIKAL}

\section{Open Architecture}

Open architecture merupakan The Third place bagi masyarakat kota, yang berfungsi sebagai ruang antara, ruang yang bukan hanya tempat tinggal (home) dan tempat kerja. The Third place adalah sebuah program yang akan membantu masyarakat kota agar bersifat humanis, terbuka, dinamis, dan produktif. Open Architecture bersifat terbuka terhadap halhal baru. Open Architecture membuka hal-hal yang bersifat tertutup (privat) menjadi societal (publik).

\section{Third place}

Dalam aktivitas sehari-hari manusia, ada 2 tempat utama yang selalu dikunjungi. Yang pertama atau First Place adalah rumah (home). Rumah adalah tempat dimana manusia bertempat tinggal dan beristirahat setelah melakukan segala aktivitas selama seharian. Rumah juga merupakan tempat lingkungan tetap seorang anak manusia yang bertumbuh dewasa dan akan memiliki pengaruh besar terhadap perkembangan manusia. Yang kedua atau Second Place ini pada umumnya berupa institusi tempat seseorang bekerja atau belajar yang memiliki jadwal tetap sehingga mengharuskan manusia untuk melakukan pekerjaan di tempat tersebut pada waktu dan hari tertentu secara terus menerus. Second Place mendorong terjadinya kompetisi dan memotivasi seorang individu untuk bisa lebih di atas makhluk sesamanya dan juga menyediakan sarana untuk hidup serta meningkatkan kualitas materi bagi kehidupan seseorang. Lalu ada satu tempat lagi yang sebenarnya dibutuhkan oleh 
manusia dalam kehidupan sehari-harinya, namun seringkali tidak disadari oleh masyarakat, yaitu Third place. Third place adalah tempat yang mewadahi kehidupan publik yang informal dan merupakan berbagai macam tempat publik yang menerima perkumpulan individu yang reguler, sukarela, informal, dan menyenangkan. Third place menjadi tempat dimana masyarakat kota dapat berkumpul secara bebas untuk bersosialisasi dengan sesama individu dan membentuk sebuah komunitas.

\section{Space dan Place}

Ada perbedaan antara space dan place. Menurut Florida (2012), dalam bukunya "The Rise of the Creative Class, Revisited", kualitas sebuah place (quality of place) dapat dilihat dari 3 aspek.

- Pertama, what's there (apa yang ada), yaitu gabungan antara lingkungan terbangun dan lingkungan alam, keadaan yang sesuai untuk mendapatkan kehidupan kreatif.

- Kedua, who's there (siapa yang ada), beragam jenis orang, berinteraksi dan memberikan tanda bahwa setiap orang dapat menciptakan kehidupan dalam sebuah komunitas.

- Ketiga, what's going on (apa yang terjadi), adanya suasana kehidupan di jalanan, café culture, seni, musik, dan orang-orang yang ikut serta dalam aktivitas di luar rumah, seluruhnya menunjukkan sifat yang aktif, menyenangkan, dan kreatif.

Space hanya sebuah ruang yang mewadahi manusia, tetapi place adalah sebuah ruang yang tidak hanya mewadahi manusia dan aktivitasnya, tetapi juga ada kehidupan yang terjadi di dalamnya, ada sebuah kebiasaan, ada sebuah kebudayaan, sejarah, identitas, ciri khas, adanya pengalaman dan suasana yang hanya dirasakan di tempat itu dan berbeda dengan tempat lain.

\section{Isu Mengenai The Third place}

Menurut observasi yang dilakukan oleh Ray Oldenburg dalam bukunya "The Great Good Place", kota-kota seperti di Amerika memiliki gaya hidup masyarakat yang bersifat individualis dan memiliki kebiasaan kerja-pulang setiap hari dan tidak ada banyak aktivitas sosial setiap harinya. Dalam keseharian seorang individu, waktunya sudah banyak disita oleh jam kerja dari pagi hingga malam. Hal ini dilakukan setiap hari dan menjadi kebiasaan masyarakat di kota tersebut. Kebiasaan ini semakin lama dibawa dan menjadi budaya hidup masyarakat. Kebiasaan ini juga mengurangi aktivitas dan interaksi antar individu dan membuat kehidupan sehari-hari manusia menjadi membosankan dan dapat memicu stres.

Seorang individu membutuhkan aktivitas sosial atau komunitas sosial informal, dimana tidak ada banyak aturan-aturan yang membatasi, tidak ada keanggotaan yang tetap, tidak perlu jadwal kegiatan yang teratur, serta tidak ada hirarki atau jabatan maupun tanggung jawab yang biasa dirasakan di tempat kerja atau tempat tinggal. Dengan adanya komunitas informal ini, dapat menjadi tempat hiburan bagi manusia, dimana sesama individu saling berinteraksi, melakukan berbagai aktivitas sosial, berbagi informasi, bercanda tawa, saling menghibur satu sama lain dan berkelompok layaknya manusia yang hidup bersama di tempat yang sama, yaitu dengan adanya Third Place

\section{Karakteristik Third place}
a. Sebagai Daerah Netral
b. Third place yang Menyamaratakan (Leveler)
c. Percakapan Sebagai Aktivitas Utama
d. Aksesibilitas dan Akomodasi
e. Adanya Pelanggan Tetap
f. Low Profile
g. Suasana yang Ceria (hiburan dan canda)
h. Seperti rumah yang Jauh Dari Rumah 


\section{Musik Indie}

Musik Indie adalah salah satu aliran musik yang sedang populer di masa kini. Kata "Indie" adalah singkatan dari kata Independent, yang berarti sebuah aliran musik dimana si artis memproduksi karya musiknya sendiri secara independen, atau diproduksi melalui label rekaman komersil independen. Dengan adanya perkembangan teknologi di masa kini, artis dapat menggunakan berbagai macam software komputer untuk merekam karyanya dan memasarkannya melalui berbagai media sosial secara online.

Label independen, juga dikenal sebagai label indie, adalah perusahaan label rekaman yang dapat memasarkan, membiayai, dan mempublikasikan artis dan karyanya, didanai secara independen dan tidak terhubung ke salah satu dari tiga label besar yaitu Universal, Sony dan Warner. Label Indie berkisar dari label yang hanya sebagai hobi rumahan hingga bisnis besar yang sangat menguntungkan.

KELEBIHAN
$\begin{aligned} & \text {-Biaya kontrak lebih murah } \\ & \text {-Lebih membebaskan } \\ & \text { kreativitas artis } \\ & \text {-Hak artis lebih besar }\end{aligned}$

Gambar 1. Perbedaan Label Indie dan Label Mayor

Sumber: Penulis, 2019

Namun, sebagian besar label indie sangat terbatas dalam hal dana. Kebanyakan dari mereka tidak mampu melakukan pembayaran besar, bonus atau kontrak rekaman besar, mereka juga tidak mampu membayar kampanye pemasaran besar atau promosi untuk popularitas musisi. Ini hal yang membuat label indie lebih sulit untuk membangun nama.

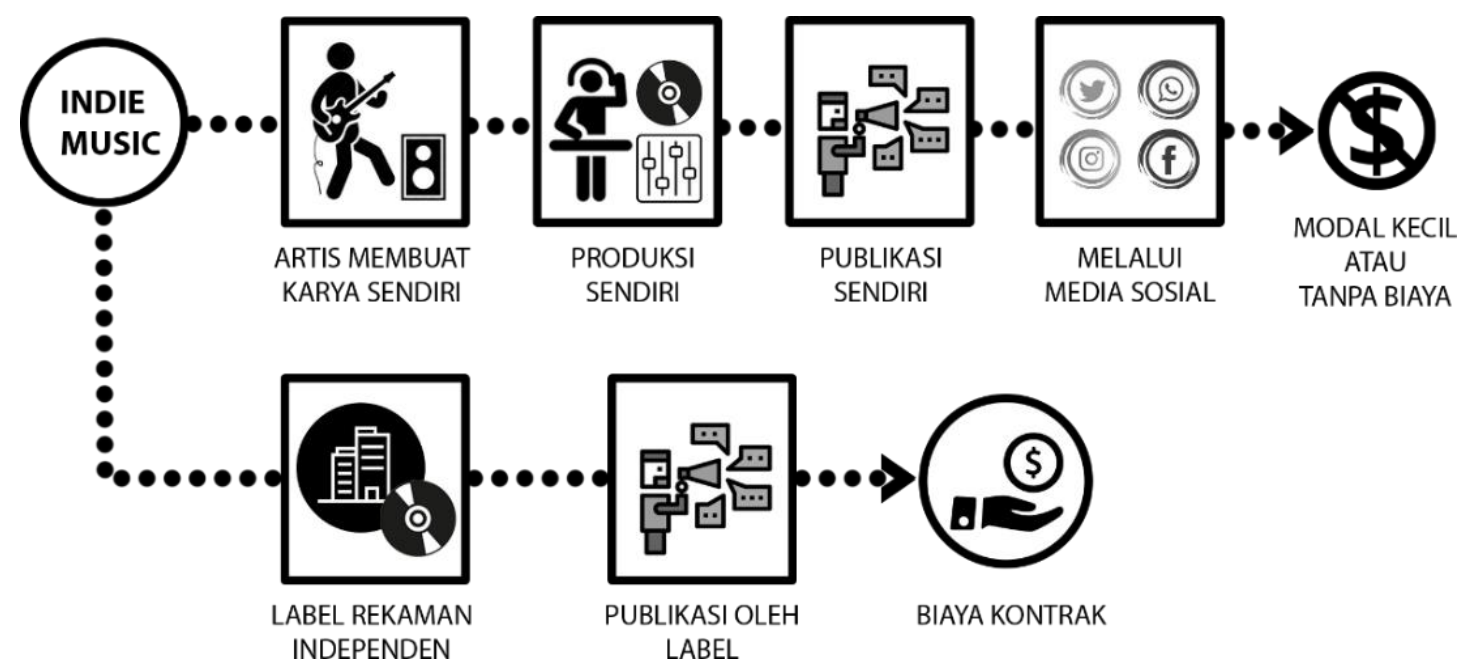

Gambar 2. Produksi Musik Indie

Sumber: Penulis, 2019 
Label rekaman mayor sendiri membutuhkan bayaran yang cukup besar untuk kontrak bagi musisi, dan cenderung mencari musisi yang sudah berpengalaman dan berpotensi besar untuk menjadi terkenal di masyarakat. Musisi indie biasanya adalah musisi lokal pemula yang dapat memproduksi karyanya secara independen, lalu perlahan-lahan berkembang hingga semakin terkenal sebelum akhirnya bisa dikontrak oleh label rekaman besar.

\section{METODE PERANCANGAN}

\section{Perumusan Ide}

Perumusan ide atau gagasan utama dalam perancangan Wadah Musik Indie Lokal ini didasarkan atas 2 aspek, yaitu :

a. Perumusan Ide Berdasarkan Objek

Karena di kawasan memiliki ciri khas yaitu sebagai salah satu pusat kesenian dan kebudayaan di Jakarta, dan dengan perkembangan industri musik yang juga dipengaruhi oleh kemajuan teknologi yang menghasilkan banyak musisi-musisi independen, maka penulis mengambil objek rancangan berupa Wadah Musik Indie Lokal.

b. Perumusan Ide Berdasarkan Tema

Tema proyek yaitu Open Architecture for The Third place diharapkan mampu menciptakan sebuah tempat yang bersifat terbuka, dapat menerima keberagaman masyarakat, mendorong masyarakat untuk berkomunitas serta menyediakan program yang sesuai dengan kebutuhan masyarakat kota dan mendukung kehidupan kota.

\section{Identifikasi Masalah}

a. Minimnya tempat publik inklusif yang dapat mewadahi masyarakat yang beragam untuk dapat berkomunitas secara informal.

b. Masyarakat kota yang semakin bersifat individualis karena kurangnya fasilitas publik yang secara khusus bertujuan untuk mewadahi berbagai aktvitas sosial informal masyarakat.

c. Minimnya tempat yang dapat mewadahi musisi indie lokal dan komunitas musik indie di kawasan.

\section{Metode Pengumpulan Data}

\section{Studi lapangan}

Studi lapangan merupakan pencarian data dengan cara langsung dari hasil pengamatan lokasi dengan cara mengamati kondisi di sekitar kawasan, mengidentifikasi kondisi eksisting tapak, dan potensi yang dapat mendukung fungsi dari objek rancangan dan juga dapat mengidentifikasi permasalahan yang ada di lokasi. Dari hasil survey lapangan tersebut maka dapat dianalisis dan menjadi acuan untuk proses perancangan.

\section{Dokumentasi}

Dalam survey lapangan tersebut menggunakan media dokumentasi, dengan cara mengumpulkan dokumen-dokumen yang terkait dengan proses pencarian data, sehingga dihasilkan informasi serta bukti yang konkrit. Metode dokumentasi digunakan untuk mendokumentasikan kondisi eksisting tapak yang telah ditetapkan di kawasan Cikini dan suasana sekitar kawasan dan beberapa bangunan yang menunjukkan ciri khas kawasan.

\section{Studi literatur}

Studi literatur yang digunakan sebagai referensi berupa buku, jurnal, artikel, dan karya ilmiah lainnya. Dalam perancangan Wadah Musik Indie Lokal ini, studi literatur dimanfaatkan untuk pencarian data yang berkaitan dengan:

- Data yang terkait dengan kawasan dan tapak yang telah ditetapkan pemerintah. Kemudian dari data yang didapat tersebut kemudian dijadikan bahan pertimbangan analisis proses 
perancangan.

- Literatur mengenai "Third place" dan "Open Architecture", karakteristik yang dimiliki dan isu-isu yang berkaitan.

- Literatur mengenai industri musik indie dan perkembangan musikindie.

\section{Studi Preseden}

Studi kasus yang digunakan sebagai referensi berdasarkan proyek-proyek arsitektur yang berkaitan dengan isu Third place dan isu musik indie dilihat dari karakteristik proyek, program ruang, dan komposisi ruang.

\section{DISKUSI DAN HASIL}

Proyek ini dinamakan "Wadah Musik Indie Lokal". Proyek ini terletak bersebelahan dengan kompleks TIM, yang di dalamnya terdapat Institut Kesesnian Jakarta, yaitu kampus seni yang dikenal menghasilkan musisi indie di Jakarta. Area Cikini juga memiliki banyak bangunan kesenian dan kebudayaan yang menjadi point of interest dalam kawasan. Program dalam proyek ini menyediakan tempat bagi masyarakat untuk berkumpul dan bersosialisasi serta menikmati musik dan bagi musisi indie untuk tampil dan berkarya di depan publik. Sesuai dengan peraturan pemerintah, site ini memiliki luas tapak sebesar $3000 \mathrm{~m} 2$, dengan luas total bangunan sebesar $6049 \mathrm{~m} 2$.

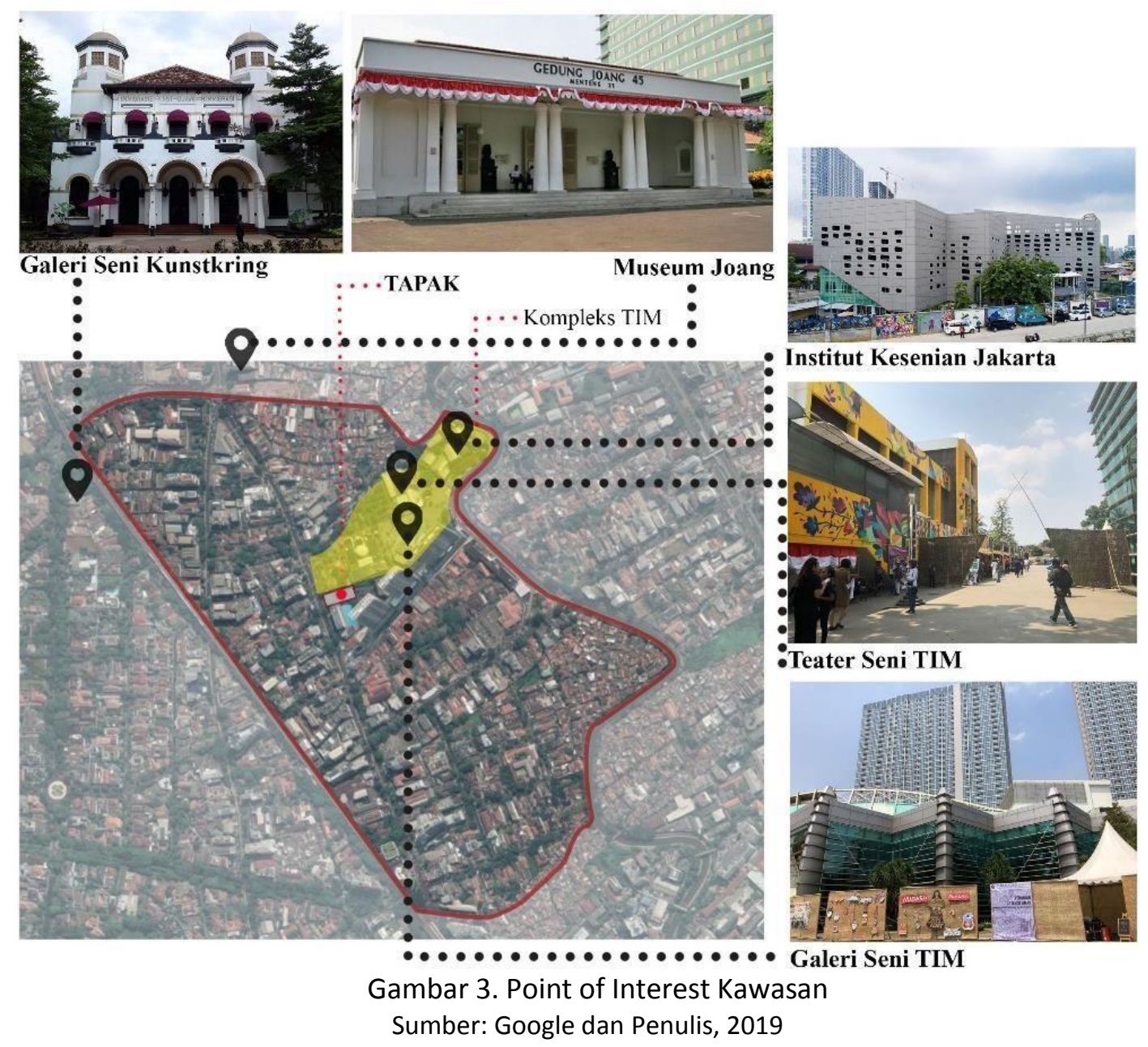




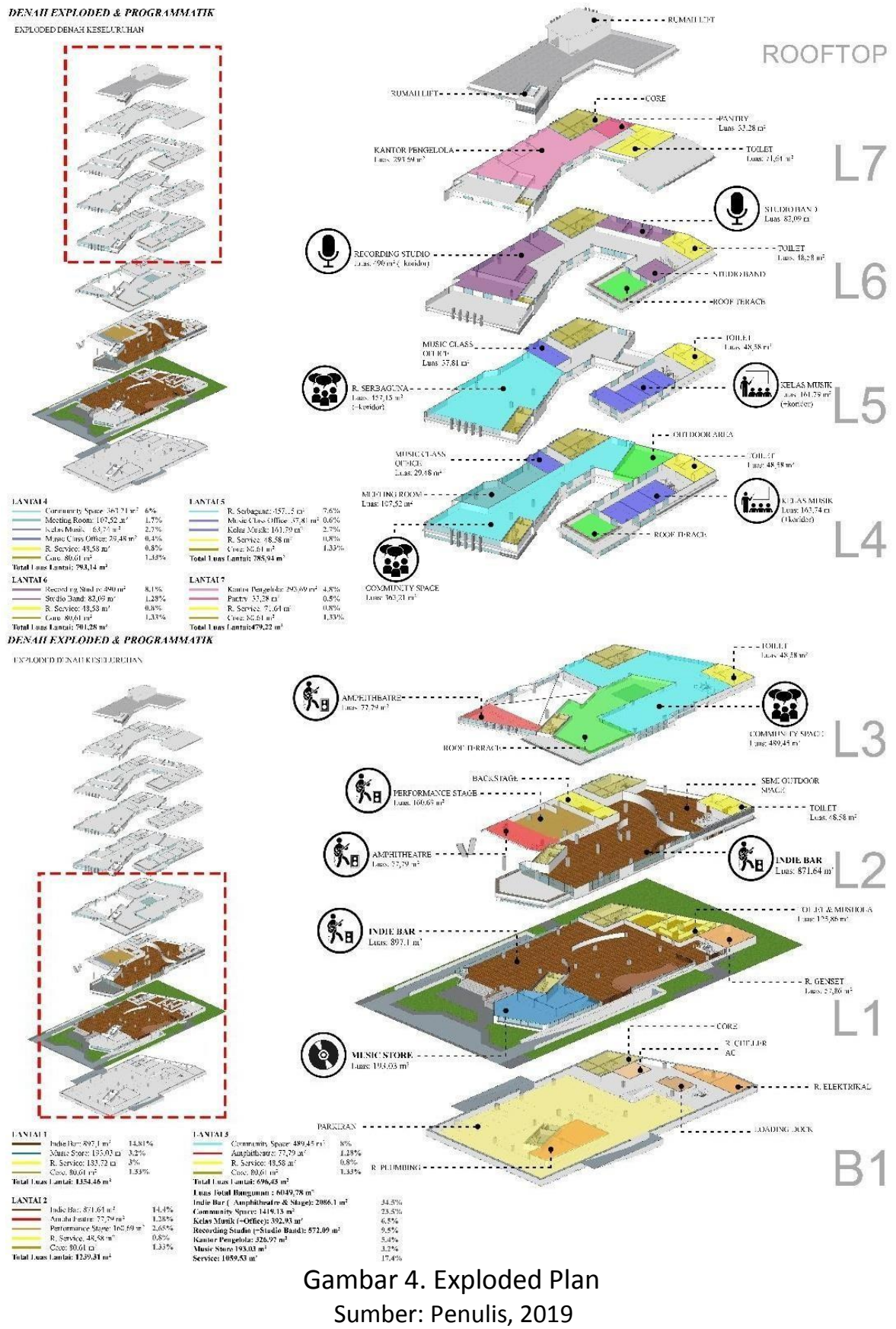

Dari diagram di atas, terdapat 5 program yaitu Indie Bar, Community Space, Music Studio, Music Class, dan Music Store. Indie Bar merupakan program utama yang menjadi fokus dari Third Place, yaitu sebuah bar dengan live music yang dibuka untuk publik dan menjadi tempat dimana musisi indie dapat tampil. Community Space adalah tempat untuk berbagai aktivitas komunitas, dimana masyarakat publik dapat berkumpul untuk berbagai macam acara pertemuan, forum, ruang diskusi bagi musisi, tempat untuk mencari ide dan inspirasi bagi musisi dalam menciptakan lagu, yang di dalamnya juga terdapat mini library untuk berbagai referensi musik. Music Classes menyediakan kelas kursus musik berbayar yang melayani untuk umum. Music Studio menyediakan studio band sewa dan studio rekaman yang dapat digunakan oleh siapapun. Music Store adalah toko musik yang menjual musik hasil rekaman musisi indie dari Recording Studio, dan beberapa macam alat musik beserta service alat musik. 


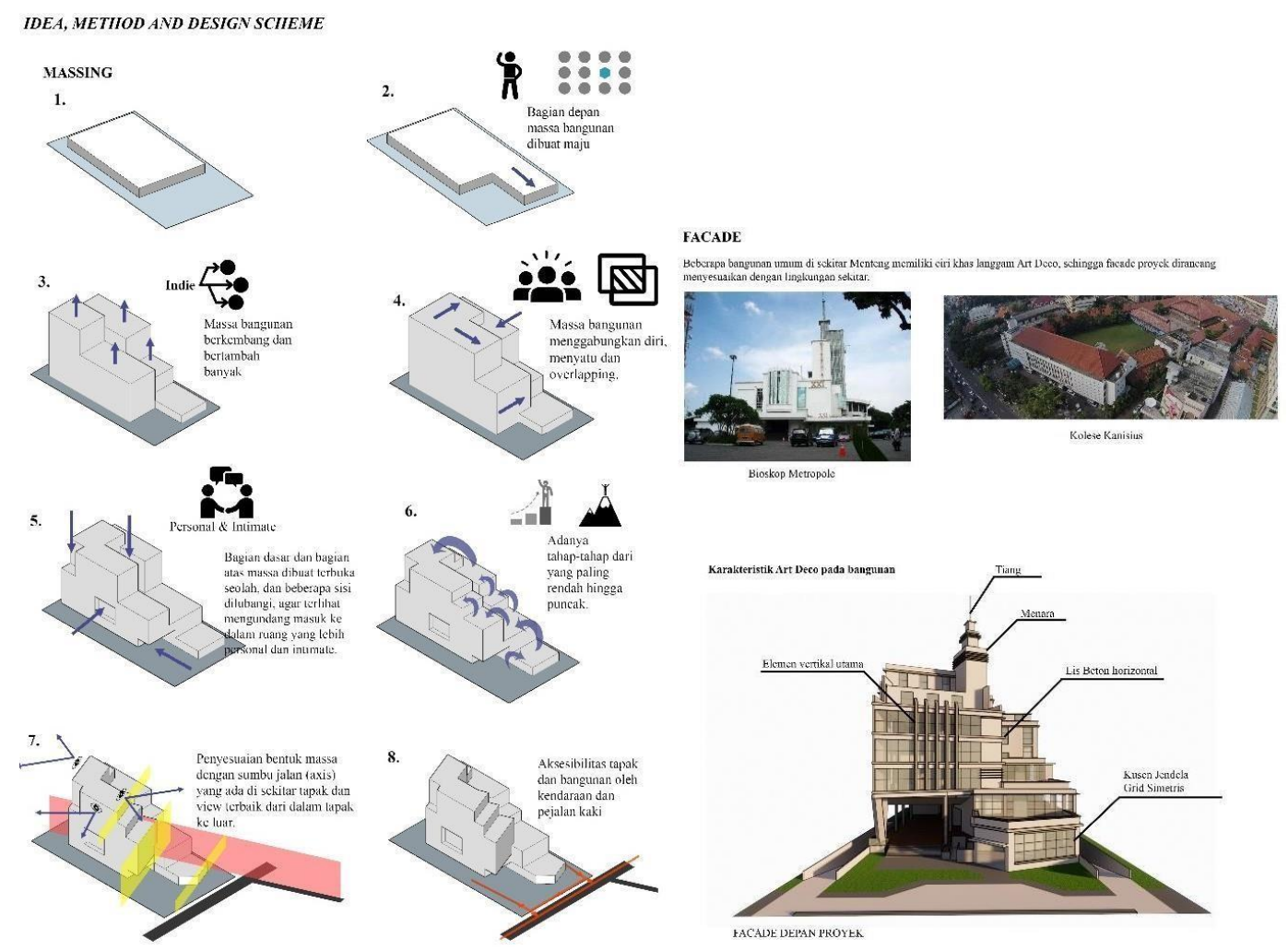

Gambar 5. Proses Massing dan Façade Sumber: Penulis, 2019

Konsep musik indie dilihat dari definisi, sejarah timeline, dan gaya lirik musiknya kemudian disusun menjadi sebuah narasi atau langkah-langkah (sequence) sebagai konsep dalam mendesain bentuk gubahan. Setiap sequence dari timeline sejarah diterjemahkan menjadi gambaran secara metafora, sebelum akhirnya diterapkan ke dalam bentuk. Lalu disesuaikan dengan analisa tapak dan lingkungan sekitar. Facade bangunan disesuaikan dengan ciri khas kawasan Menteng. Beberapa bangunan umum di Menteng seperti Bioskop Metropole dan Sekolah Kanisius memiliki ciri khas facade dengan gaya Art Deco. Maka facade bangunan proyek dibuat dengan adanya elemen-elemen Art Deco namun dengan gaya yang lebih modern seperti ada banyaknya kaca jendela di sepanjang bangunan.

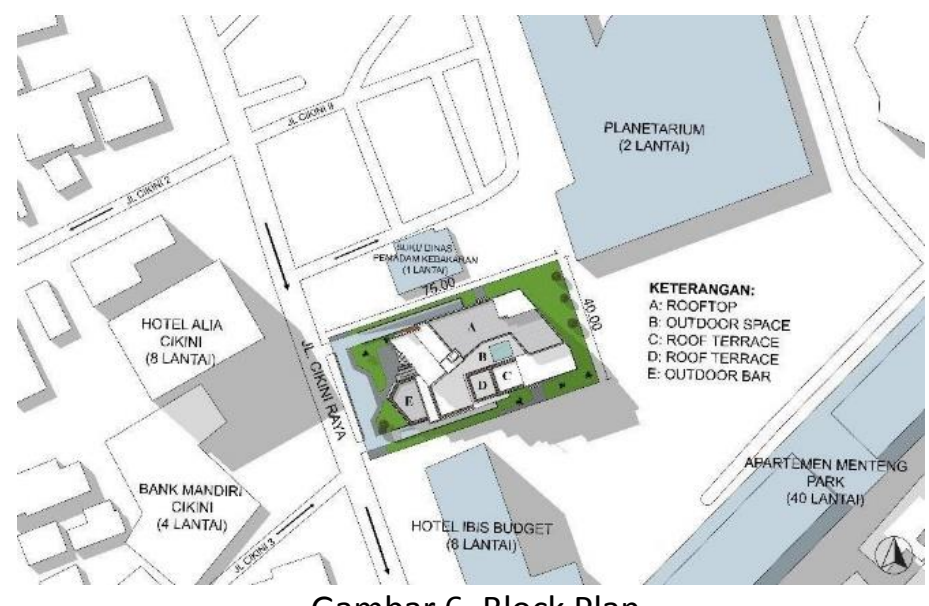

Gambar 6. Block Plan

Sumber: Penulis, 2019 
Bangunan ini juga menyediakan konektor ke bangunan sekitar yaitu ke Hotel Ibis Budget dan ke Kompleks TIM. Pada sisi sebelah utara dan selatan, ada side entrance yang dapat diakses oleh pejalan kaki yang menghubungkan area sekitar Planetarium di TIM dengan proyek. Ada pula bukaan yang menghadap ke sisi samping lbis Budget, sehingga dapat memudahkan penghuni Hotel lbis budget untuk mengakses bangunan proyek maupun untuk menuju ke kompleks TIM. Konektor ini memudahkan akses bagi pedestrian dan membuat bangunan ini menjadi lebih permeable.
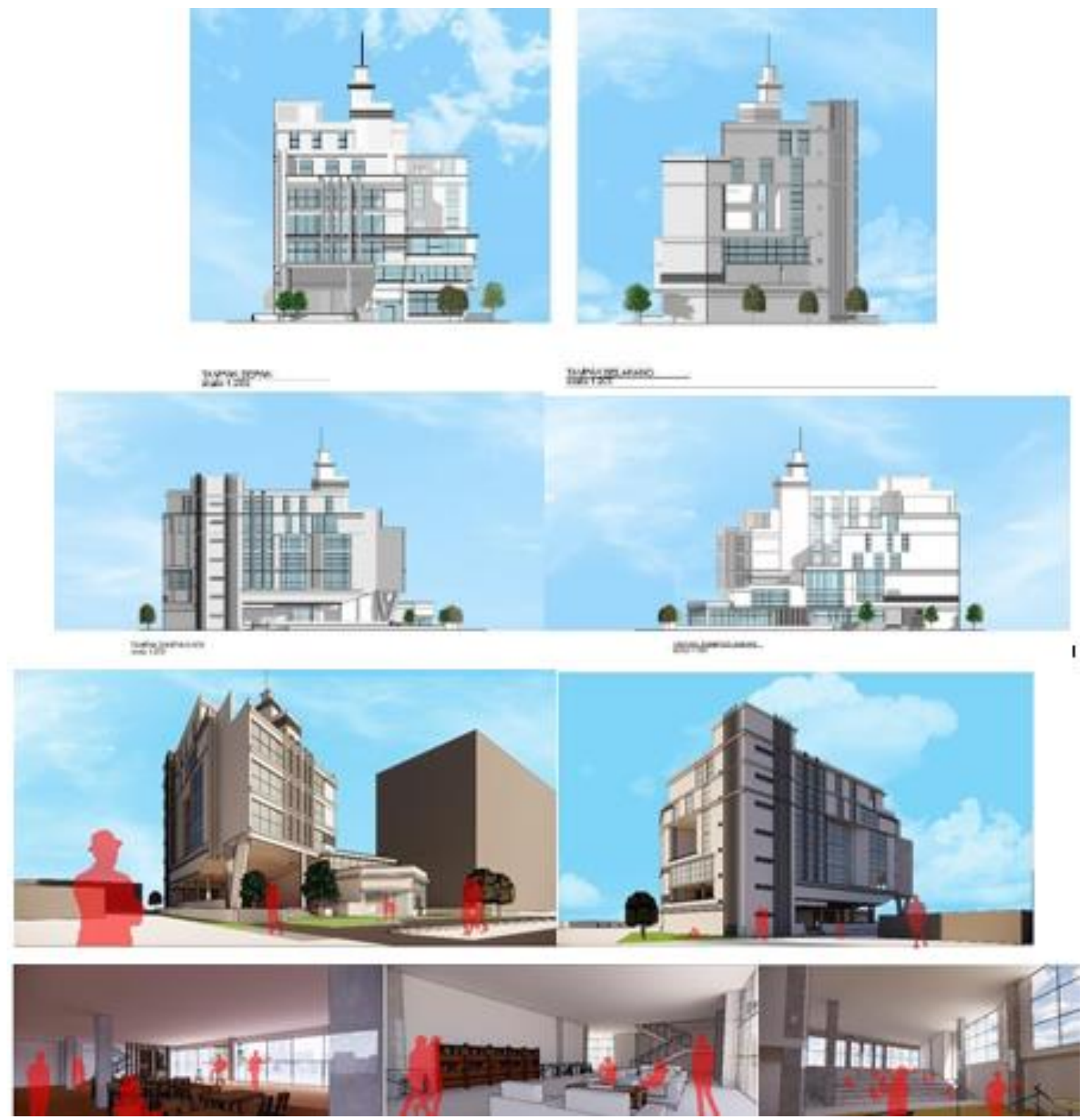

Gambar 7. Tampak dan Perspektif Exterior Interior. Sumber: Penulis, 2019

Gambar di atas menunjukkan suasana bangunan exterior dan interior. Indie Bar menyediakan ruang Amphitheater yang luas dan memudahkan penonton untuk menyaksikan acara musik dengan adanya perbedaan level. Indie Bar di lantai 2 merupakan ruangan untuk musik full band sehingga diberi peredam suara pada dinding di sekitar ruangan. Berbeda dengan Indie Bar di lantai 1 yang semi outdoor, yang dibuat khusus untuk musik akustik agar tidak menimbulkan kebisingan keluar bangunan 


\section{KESIMPULAN DAN SARAN}

Individualisme merupakan salah satu permasalahan yang terjadi dalam kehidupan masyarakat. Hal ini disebabkan oleh salah satunya kebiasaan manusia dalam menghabiskan sebagian besar waktunya bekerja dan beristirahat di rumah dan tanpa adanya kegiatan sosial yang dapat rutin dilakukan setiap hari dengan sesamanya, apalagi dengan adanya media sosial yang membuat manusia dapat berkomunikasi hanya dengan perangkat elektronik dan tidak bertemu secara langsung. Open Architecture dapat menjadi solusi desain untuk isu indidviualisme sebagai tempat berkumpulnya komunitas masyarakat untuk bersosialisasi dan sebagai tempat publik informal. Penelitian ini masih perlu adanya dukungan yang positif untuk mengembangkan desain dan ide yang dapat menjadi solusi untuk isu individualisme yang terjadi dalam masyarakat.

\section{REFERENSI}

Florida, R. (2012). The Rise of The Creative Class, Revisited. New York: Basic Books.

Fonarow, W. (2006). Empire of Dirt: The Aesthetics and Rituals of British Indie Music.

Connecticut: Wesleyan University Press.

Mcdonald, H. (2019). How Indie Record Label Works di

https://www.thebalancecareers.com/signing-with-an-indie-label-2460744 (diakses 25

Agustus2019)

Oldenburg, R. (1989). The Great Good Place: Cafes, coffee shops, bookstores, bars, hair salons and other hangouts at the heart of community. Philadelphia: Da Capo Press.

Oswald, V. (2019). Indie Rock: Finding an Independent Voice. New York: Greenhaven Publishing.

Sanchez, D. (2018). Indie Labels Now Account for 39.9\% of the Global Recorded Music Market di https://www.digitalmusicnews.com/2018/12/04/win-indie-labels-artists-2017-report/ (di akses 25 Agustus 2019)

Worldwide Independent Report. (2018). Wintel Worldwide Independent Market Report 2018, (di akses 25 Agustus 2019) 